Campos-García, I. (2022). ¿Por qué somos diferentes?: Directores y profesores en el epicentro de la reforma educativa española. Revista de Investigación Educativa, 40(1), 275-302.

DOI: http://dx.doi.org/10.6018/rie.464421

\title{
¿Por qué somos diferentes?: Directores y profesores en el epicentro de la reforma educativa española
}

\section{Why are we different?: Principals and teachers at the center of the Spanish educational reform}

\author{
Irene Campos-García' \\ Universidad Rey Juan Carlos
}

\begin{abstract}
Resumen
A pesar de las últimas reformas y esfuerzos emprendidos, el sistema educativo español continúa arrojando datos que denotan bastante ineficacia: dentro del contexto europeo presenta uno de los niveles más bajos de gasto público en educación, se sitúa a la cola del ranking PISA, muestra alarmantes cifras de fracaso escolar y encabeza el listado de abandono temprano de la educación y la formación. A partir de un análisis cuantitativo y cualitativo de los datos arrojados por TALIS, el objetivo de este trabajo se ha concretado en examinar y precisar los aspectos que, vinculados al personal docente, marcan la diferencia entre el sistema español y aquellos europeos que lideran los rankings de éxito escolar. Los resultados revelan una sorprendente similitud en lo que a dificultades y desafíos se refiere; sin embargo, existe gran divergencia en tres aspectos clave que tienen que ver con la llegada a la profesión, el desarrollo durante la profesión y la movilidad hasta culminar la carrera docente. Las conclusiones obtenidas resultan útiles para trazar los ejes de actuación sobre los que podría asentarse la mejora del sistema educativo español, con el consiguiente impacto sobre los niveles de competitividad y bienestar social.

Palabras clave: directores; profesores; formación; desarrollo profesional.
\end{abstract}

\begin{abstract}
Despite the latest reforms and efforts undertaken, the Spanish educational system continues showing data that denotes its high ineffectiveness: within the European context it has one of
\end{abstract}

1 Correspondencia: Irene Campos-García, irene.campos@urjc.es. Universidad Rey Juan Carlos (España). 
the lowest levels of public spending on education, it is at the bottom of the PISA ranking, it shows alarming figures of school failure and it heads dropout rate lists. Based on a quantitative and qualitative analysis of the data from TALIS, this article aims to examine and specify the conditions of teaching staff that make the difference between the Spanish system and European system heading school success rankings. The findings reveal a surprising similarity in terms of difficulties and challenges; however, there is great divergence in three key aspects related to entry into the profession, professional development and mobility until the end of the teaching career. The conclusions obtained are useful for tracing the lines of action on which the improvement of the Spanish educational system could be based, with their consequent impact on the levels of competitiveness and social well-being of teaching staff.

Keywords: school principals; teachers; training; professional development.

\section{Introducción}

En el empeño de identificar los retos actuales que plantea el sistema educativo español, resulta sorprendente y curioso que informes y/o artículos publicados ya sea hace veinte, diez o un año, hagan referencia, casi literalmente, a idénticos desafíos. En España, se lleva prácticamente dos décadas discutiendo sobre lo mismo: a nivel macro, de consenso político, estabilidad legislativa e inversión en educación y, a nivel micro, de autonomía en las escuelas, gestión de recursos humanos y desarrollo profesional docente, principalmente.

Mismo debate y, más o menos, mismos resultados. Porque a pesar de los esfuerzos y reformas emprendidas, el sistema español sigue arrojando indicadores de calidad que denotan bastante ineficacia en comparación con otros sistemas educativos. España presenta, dentro del contexto europeo, uno de los niveles más bajos de gasto público en educación, se sitúa a la cola del ranking PISA, muestra alarmantes cifras de fracaso escolar y encabeza el listado de abandono temprano de la educación y la formación (INEE, 2019, 2020; OECD, 2019a).

Estos datos preocupan dadas las consecuencias y costes para los individuos y la sociedad, tanto desde el punto de vista del mercado de trabajo como del bienestar en general (INEE, 2019, 2020). Es por ello que la Comisión Europea estableció la Estrategia Europa 2020 con la intención de instar a los países a cumplir ciertos objetivos relacionados con el aprendizaje permanente, la calidad, la igualdad y la innovación y, de esta forma, mejorar los resultados educativos. No obstante, tan grande resulta la brecha española en algunos indicadores que dicho acuerdo ha contemplado objetivos mucho menos ambiciosos - por ejemplo, uno de ellos es situar por debajo del $10 \%$ el porcentaje de personas que no completan la Educación Secundaria Obligatoria, habiendo elevado para España esa meta al 15\% (European Commission, 2019).

A partir de un análisis cuantitativo y cualitativo derivado de las bases de datos europeas que ofrece la OCDE sobre TALIS, este trabajo tiene por objetivo examinar y comparar los aspectos que hacen la diferencia entre el sistema educativo español y el resto de sistemas europeos. Concretamente, se pone el énfasis en el estudio de factores vinculados al personal docente, por ser éste el principal activo del sistema educativo y un input sobre el que se puede incidir. Se trata, por tanto, de aportar y precisar las actuaciones de política educativa que podrían contribuir a reducir las diferencias y 
aproximar al sistema español a los objetivos europeos. Por un lado, la OCDE recoge, para cada país, los aspectos que caracterizan su sistema educativo, realizando una comparativa general que no permite profundizar en las similitudes o diferencias que subyacen entre distintos sistemas educativos. Por otro lado, la literatura previa enmarcada en el contexto español se ha enfocado en la comparación de sistemas educativos por pares o entre pocos países (p.ej., García Perales y Martín Sánchez, 2012; Granados, 2015, Rubio, 2017; Segura, 2009). Es por ello que este estudio puede añadir una visión más dilatada y completa de la realidad europea.

Este trabajo se estructura como sigue. El segundo apartado, a partir de los indicadores que permiten evaluar el éxito de un sistema educativo, muestra un diagnóstico del sistema español. El tercer apartado describe el método, especificando cuestiones sobre la muestra, los procedimientos y las técnicas utilizadas. A continuación, la cuarta sección muestra y discute los resultados. Finalmente, se exponen las conclusiones.

\section{Sistema educativo español:Antecedentes y contexto actual}

El ciclo expansivo iniciado a finales del siglo XX generó un impacto positivo en las principales magnitudes macroeconómicas, favoreciendo también la inversión y el gasto público en educación. Sin embargo, la llegada de la crisis económica derivó en recortes de las partidas presupuestarias dedicadas a educación que incidieron de manera drástica y negativa sobre los resultados y la calidad del sistema educativo (ver, por ejemplo, Panorama de la Educación (OCDE, 2007-2015) o Sistema Estatal de Indicadores de la Educación (INEE, 2011-2015)).

En cuanto al gasto público destinado a educación en relación al PIB, éste alcanzó su máximo en 2009 con un porcentaje del 4,99\% - 53.895 millones de euros - y protagonizó un significativo descenso hasta 2013 que redujo la cifra al 4,38\% -44.958 millones de euros. Desde 2015, de forma paralela a la recuperación de la economía española, el gasto en educación se ha ido incrementando ligeramente, hasta llegar a los 51.275,9 millones de euros en 2018 (INEE, 2019). No obstante, España, con un 4\% de gasto público como porcentaje del PIB, sigue alejada de la media de los países de la UE-27 -4,6\% del PIB en 2019 (Eurostat, 2020a) ${ }^{2}$ - y de la OCDE, que supera los 5 puntos (OECD, 2019a). Existe también brecha en cuanto al gasto medio por alumno en instituciones públicas y privadas en euros y al PIB por habitante: España mantiene una distancia significativa respecto a países como Austria, Bélgica, Finlandia, Suecia o Reino Unido (Eurostat, 2020a; INEE, 2019; OECD, 2019a).

Malas cifras también acompañan a algunos procedimientos y prácticas docentes que inciden en la calidad del profesorado. En cuanto a los procedimientos de acceso a la profesión docente, numerosas voces han criticado el modelo español (p. ej., Gálvez, 2010; Manso, Matarranz y Valle, 2019; Muñoz, 2010). En comparación con los sistemas de concurso de méritos o los procesos de selección abierta propios de los sistemas educativos más descentralizados, en España persiste el sistema de oposición en la enseñanza pública. Numerosos países europeos realizan una selección

2 Por ejemplo, Suecia, Noruega, Finlandia, Bélgica, Reino Unido o Dinamarca tienen porcentajes entre $5,6 \%$ y $6,9 \%$ (Eurostat, 2020a). 
previa al comienzo de la formación docente: limitan las plazas ofertadas y preparan a un número reducido de futuros profesores en lugar de formar a un gran número de estudiantes y seleccionar después a algunos de ellos para acceder a un puesto de trabajo (Gálvez, 2010). Esto último es lo que sucede en España donde, además, la oposición otorga un peso mucho mayor a los conocimientos académicos de los futuros profesores que a sus capacidades o habilidades para la enseñanza, lo que va en detrimento de la selección de las personas más cualificadas para la tarea docente (OECD, 2018a).

Respecto a la formación inicial del profesorado, ciertos aspectos relevantes relacionados con la pedagogía, la enseñanza en entornos de capacidades dispares, el comportamiento del alumnado o la gestión de aula están en España menos presentes que en la mayoría de países. En la etapa de iniciación a la profesión docente, el sistema educativo español también presenta porcentajes por debajo del promedio en lo que a programas de iniciación profesional y tutoría se refiere - menos del 10\% del profesorado participa como receptores o tutores en actividades de mentorización (OECD, 2019b).

La formación continua del profesorado también acumula quejas pese a ser crucial en la mejora de la práctica docente y desarrollo profesional (Desimone, 2009; Nieto y Alfageme-González, 2017; OECD, 2019a; Tiana, 2011). Se critica que dicha formación está alejada del aula y se adecua poco a las necesidades y demandas actuales del profesorado (OECD, 2019a). España es uno de los países europeos donde los docentes reconocen invertir una mayor cantidad de horas a la semana a actividades de formación y desarrollo profesional, aunque la autoobservación u observación entre compañeros, que ha demostrado su utilidad a la hora de reflexionar, evaluar y conseguir mejorar la calidad del proceso de enseñanza y aprendizaje (Fuertes Camacho, 2011; Ulloa y Gajardo, 2016), apenas la practican el 19\% de los docentes - frente al promedio del $40 \%$ de los países de la OCDE (OECD, 2019a).

No obstante, el sistema educativo español puede presumir de altos índices de carrera docente vocacional y buenos salarios - el salario inicial medio y el salario promedio tras 15 años de experiencia es superior a la media europea y de la OCDE. En general, los docentes españoles muestran también buenas cifras respecto a su satisfacción laboral, aunque son muchos los que consideran que la profesión docente no está bien ni suficientemente valorada por la sociedad (OECD, 2019a). Datos positivos también se refieren al incremento de las mujeres en los puestos de responsabilidad y dirección - pese a que la presencia de mujeres en la profesión docente es mayoritaria, en 2008 sólo había un 39,6\% de directoras en centros de enseñanza de régimen general no universitaria, incrementándose este porcentaje en 2018 hasta el 49,3\%-, lo que constituye un avance en la igualdad y la reducción del techo de cristal (Campos-García, 2017).

En definitiva, el balance en relación a los resultados del sistema educativo español es negativo. La esperanza de vida en educación, pese a haber aumentado desde 2011, es de 18,7 años - un dato por debajo de países como Finlandia, Suecia, Países Bajos, Bélgica o Dinamarca (INEE, 2019). El alumnado pasa, de media, menos tiempo en el sistema educativo $\mathrm{y}$, además, obtiene resultados por debajo de la media de la OCDE que le sitúan a la cola de Europa (OECD, 2019c). La tasa de escolarización a los 17 años, así como la tasa de idoneidad en la edad del alumnado de educación obliga- 
toria, también aparecen ligeramente por debajo de la media europea. Por su parte, las tasas brutas de graduados en ESO y Bachillerato, aunque se han incrementado desde 2006, también denotan altos índices de fracaso escolar y abandono temprano de la educación y la formación. Preocupa, sobre todo, que España es el país europeo con mayor abandono temprano: en 2009 presentó una tasa de abandono del 30,9\% y lideró la estadística europea en 2010, 2011 y 2013, volviendo a la primera posición en 2017, 2018 y 2019. Frente a una media de la UE-27 en 2019 de 11,9\%, la cifra española es del 21,4\% (algo superior a la del resto de países del arco periférico del este al sur de Europa).

En relación a la educación superior, si bien es cierto que, desde 2014, España supera este objetivo, el nivel de formación de la población de 25 a 64 años sigue 18 puntos por debajo de la media europea - en los países de la UE el 78,1\% de la población adulta posee nivel de formación de segunda etapa de educación secundaria o superior (INEE, 2019).

Estos resultados evidencian marcadas consecuencias sobre el mercado laboral. Por un lado, España es el segundo país europeo con mayor tasa de desempleo joven - 2019 cerró con un $30 \%$ de los menores de 25 años en paro, frente al promedio del 14,1\% en la UE-27 y 15,3\% en la zona euro (Eurostat, 2020b) y dicha tasa se ha disparado en 2020 hasta el 37,7\%, duplicando las tasas medias de la UE y la zona euro. A finales de 2019 , alrededor del 17\% de jóvenes entre 25 y 34 años estaban desempleados y para el conjunto de la población entre 25 y 64 años la tasa de paro fue del 13,7\% (INE, 2020) - esta última dobla a la media europea, que se situó en 6,2\% (Eurostat, 2020b). Por otro lado, en España existe un desajuste entre la enseñanza y el mercado de trabajo, así como importantes desequilibrios en cuanto a la cualificación de las personas y los puestos que ocupan, lo que favorece altos índices de desempleo estructural -en torno al 15\% en 2019 (INE, 2020).

\section{Métodos}

A fin de poder identificar y comparar, en el marco europeo, los aspectos que marcan la diferencia entre los distintos sistemas educativos, en primer lugar se procedió a la descarga de todas las bases de datos TALIS $2018^{3}$. Seguidamente, se seleccionaron aquellos países europeos que contenían, atendiendo a los pesos muestrales de los centros y el profesorado, una mayor tasa de respuesta, estando proporcionalmente representadas la región norte - Reino Unido, Dinamarca, Finlandia, Noruega y Suecia-, la central -Francia, Países Bajos, Bélgica, Austria y República Checa- y la sur - Portugal, España, Italia, Croacia y Bulgaria. En segundo lugar, se clasificaron, para cada país, las bases de datos según la procedencia de la información (directores y profesores) y los niveles educativos (primaria y/o secundaria). La Figura 1 recoge la información relativa a la composición de la muestra (nótese que la tasa de participación española es la más altas de todos los países participantes).

3 TALIS es promovido desde 2008 quinquenalmente por la OCDE, quien ofrece todas las bases de datos nacionales e internacional para SAS, STATA y SPSS. 


\begin{tabular}{lcc}
\hline PAÍS & DIRECTORES & PROFESORES \\
\hline Austria & 277 & 6.999 \\
\hline Bélgica & 492 & 7.919 \\
\hline Bulgaria & 200 & 2.862 \\
\hline Croacia & 345 & 6.019 \\
\hline Dinamarca & 416 & 6.263 \\
\hline España & 832 & 14.653 \\
\hline Finlandia & 148 & 2.851 \\
\hline Francia & 380 & 4.435 \\
\hline Italia & 192 & 3.612 \\
\hline Noruega & 193 & 4.154 \\
\hline Países bajos & 264 & 3.388 \\
\hline Portugal & 395 & 7.227 \\
\hline Reino Unido & 319 & 4.385 \\
\hline República Checa & 219 & 3.447 \\
\hline Suecia & 546 & 8.119 \\
\hline
\end{tabular}

Figura 1. Composición de la muestra por país

Seguidamente, a partir de las preguntas incluidas en los cuestionarios de TALIS -Principal Questionnaire y Teacher Questionnaire-, se identificaron y seleccionaron las variables relacionadas con el ejercicio de la profesión docente que pueden resultar factores controlables y sobre los que se puede incidir ${ }^{4}$. Específicamente, las variables objeto de análisis se muestran en la Figura 2.

\begin{tabular}{|c|c|}
\hline \multicolumn{2}{|r|}{ Cuestionario dirigido a directores } \\
\hline Número & Contenido \\
\hline 07 & Actividades de desarrollo profesional en las que menos participan \\
\hline 08 & Necesidades de formación y desarrollo profesional \\
\hline 09 & Barreras al desarrollo profesional \\
\hline 29 & $\begin{array}{l}\text { Aspectos relacionados con el profesorado que limitan la capacidad y } \\
\text { éxito del centro }\end{array}$ \\
\hline 31 & Programas y actividades de iniciación a nuevos profesores \\
\hline 33 & $\begin{array}{l}\text { Formación impulsada por el centro en los programas de iniciación a } \\
\text { nuevos profesores }\end{array}$ \\
\hline 36 & Utilidad del mentoring \\
\hline \multicolumn{2}{|r|}{ Cuestionario dirigido a profesores } \\
\hline 06 & Aspectos en los que se sienten poco preparados \\
\hline 18 & Horas invertidas en foramción y desarrollo profesional \\
\hline 22 & Actividades menos empleadas para su desarrollo profesional \\
\hline 26 & Beneficios del desarrollo profesional sobre las practices docentes \\
\hline 27 & Necesidades del desarrollo profesional \\
\hline 28 & Barreras al desarrollo professional \\
\hline 32 & Motivos de fracaso escolar relacionados con el profesorado \\
\hline 54 & Sentimientos hacia la profesión docente \\
\hline
\end{tabular}

Figura 2. Variables seleccionadas para el análisis

4 Se excluyeron algunas variables relacionadas con las características del personal que se consideran factores fijos o no controlables. 
Por último, se procedió al análisis estadístico mediante SPSS. Específicamente, se calcularon, para cada variable, la distribución de frecuencias y las medidas de posición centrales y de dispersión a fin de facilitar la comparativa europea.

\section{Análisis y Discusión de los Resultados}

A continuación, se muestran las figuras que contienen la información cualitativa vinculada a las variables analizadas en función de la mayor frecuencia de respuesta, la media y/o la moda (ver detalle de la información cuantitativa en Anexo I). La Figura 3 recoge las respuestas de los directores. 


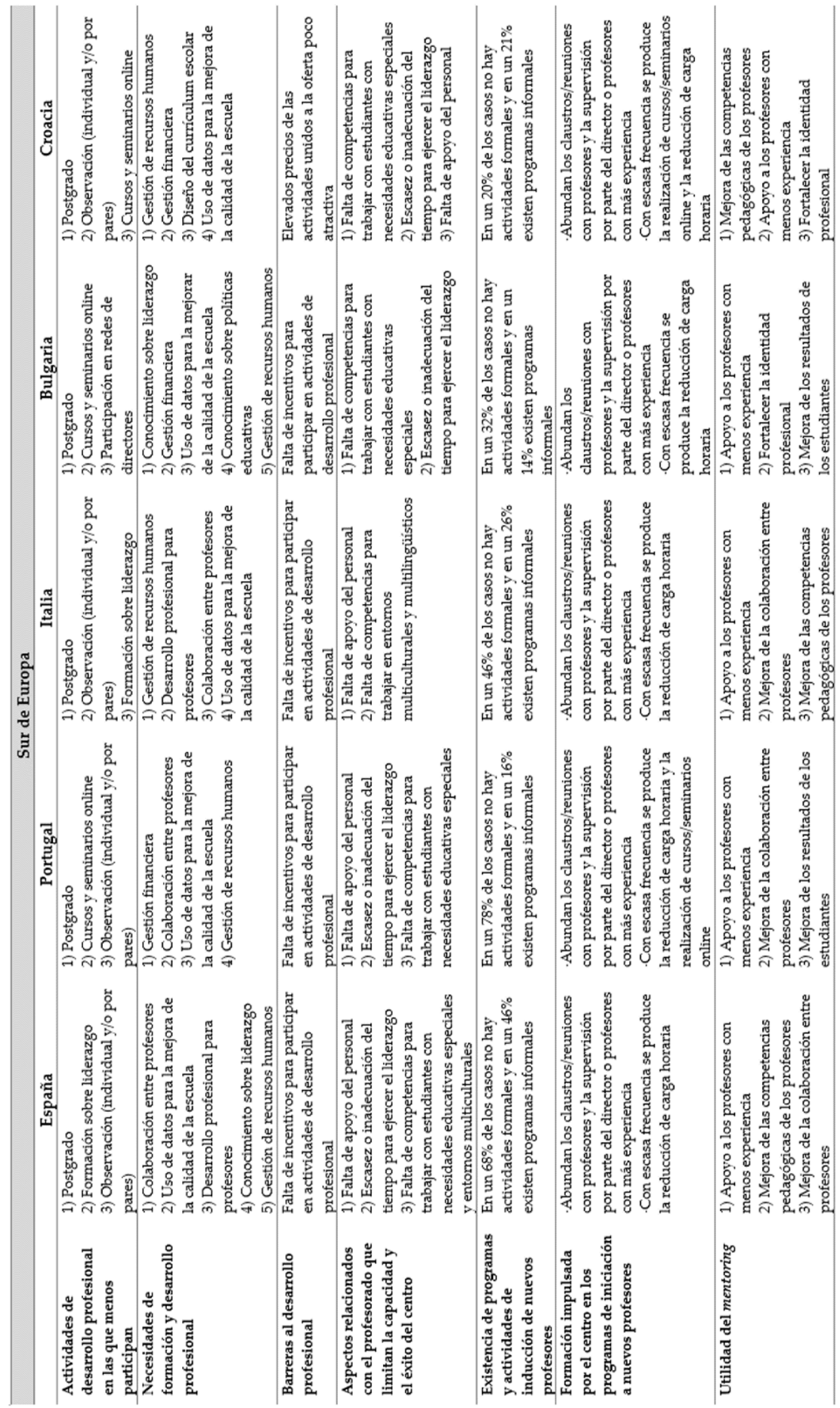




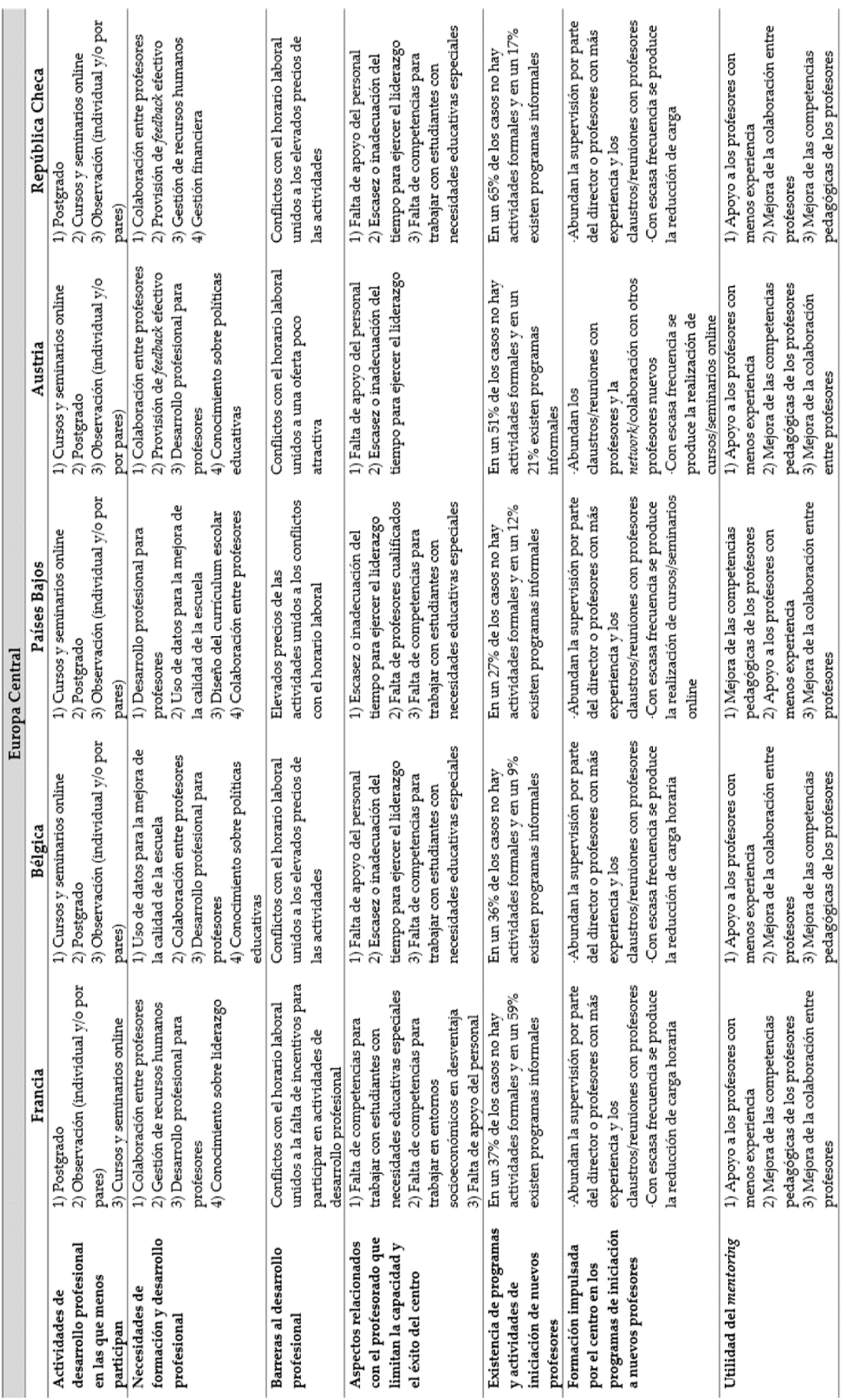




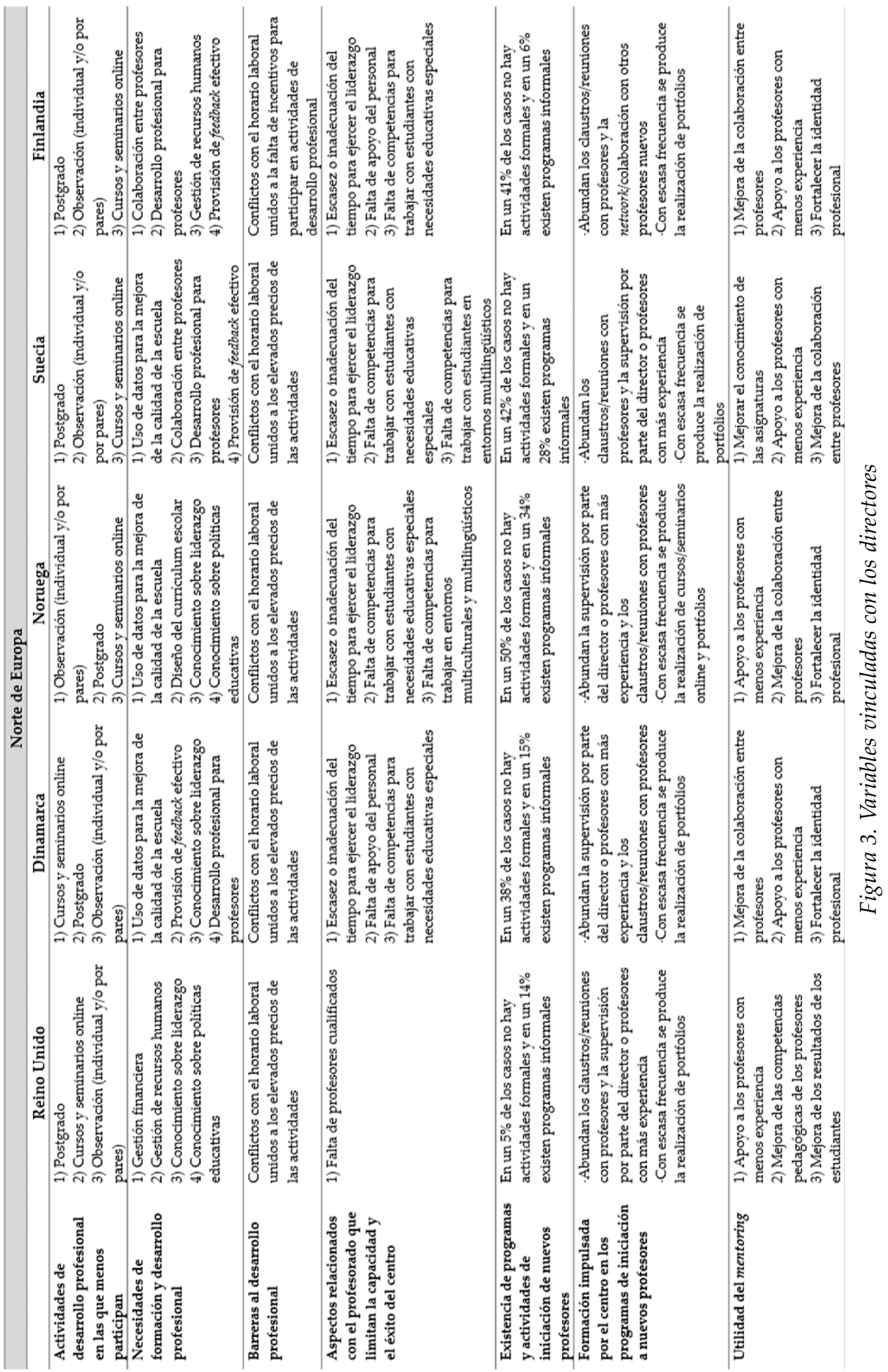


Por lo que respecta a las actividades de desarrollo profesional, los directores españoles reconocen que aquéllas que acumulan una mayor participación son los cursos presenciales sobre su especialidad y metodologías docentes, mientras que con escasa frecuencia participan en programas formales de cualificación - máster y $\mathrm{PhD}-$, cursos y seminarios sobre liderazgo y actividades de tutoría y/u observación entre directores. La comparativa europea pone de relieve que todos los países del sur de Europa registran respuestas muy similares, siendo los programas de postgrado las actividades menos seguidas. Respuestas parecidas también se encuentran en los países del centro y norte de Europa, que apuntan, en su mayoría, que las actividades con menor tasa de participación son los cursos y seminarios online y los programas formales de cualificación. No obstante, sorprende en este apartado comprobar que únicamente los directores españoles (junto con los italianos) son los únicos que acusan participar con poca frecuencia en programas sobre liderazgo. El liderazgo escolar es un factor crítico que se relaciona con la mejora de los resultados del centro educativo a través de la influencia en la motivación y las capacidades de los profesores, así como en el clima escolar y en su entorno (OECD, 2008). Sin embargo, en el contexto español ha existido durante años una cultura escolar que ha impedido, en gran medida, que los directivos escolares puedan ejercer un liderazgo pedagógico, convirtiéndose éste más en una propuesta teórica que en una práctica real (Bolívar, 2019; Bolívar, Caballero y García-Garnica, 2017).

En relación a las principales necesidades de formación y desarrollo profesional, los directores españoles demandan, en primer lugar, más formación en métodos que fomenten y promuevan la colaboración entre profesores - esta necesidad está presente, a excepción de en algunos países del norte de Europa, en el listado de necesidades de la gran mayoría de directores europeos. Con una media ligeramente inferior, los directores españoles señalan la necesidad de saber utilizar e interpretar los datos contribuyan a mejorar la calidad de los centros, siendo este aspecto también una necesidad común para casi todos los países europeos. Frecuente también resulta para la mayoría de directores la tercera petición española, que se refiere a la formación en el diseño de actividades de desarrollo profesional con/para profesores, las cuales promueven el aprendizaje dentro de los centros y convierten a éstos en comunidades profesionales de aprendizaje (Kools y Stoll, 2016). En línea con los resultados obtenidos en relación a la escasa participación en programas sobre liderazgo, los directores españoles (y los de algunos pocos países más) también echan en falta un mayor conocimiento y comprensión de las últimas novedades en investigación y teorías sobre liderazgo. Finalmente, la gestión de recursos humanos se posiciona en España, al igual que en otros muchos países, como una demanda creciente. En definitiva, los directores europeos apuntan, en general, necesidades muy similares en lo que a su formación y desarrollo profesional respecta.

Las respuestas referidas a las principales barreras al desarrollo profesional sí son discrepantes. Mientras la mayoría de directores europeos subraya los conflictos con el horario laboral, así como los elevados precios de las actividades o la falta de atractivo en la oferta como principales obstáculos, en España (y también en Portugal, Italia y Bulgaria) la falta de incentivos resulta el factor más condicionante - el $35 \%$ de los 
directores de la OCDE lo señalan como principal impedimento, mientras que en España el porcentaje es del 72\% (OECD, 2019b).

Atendiendo a los problemas que, vinculados a directores y profesores, dificultan el proporcionar una enseñanza de calidad, la falta de apoyo del personal se sitúa en España como el factor más limitante - al igual que en Portugal, Italia, Bélgica, Austria y República Checa. Dicha falta de apoyo también aparece, aunque en posiciones más abajo, en el listado de una amplia mayoría de países europeos. La escasez o inadecuación del tiempo dedicado a ejercer el liderazgo también es, para casi todos los países, un factor que afecta negativamente a la calidad de la enseñanza.

En cuanto a la existencia de programas y actividades de inserción de nuevos profesores (bien sean noveles o nuevos en un determinado centro), los directores españoles, junto con los portugueses y los checos, reconocen, en una proporción significativamente mayor a la del resto de países, no disponer en sus centros de actividades y programas formales estructurados de inducción -éstos incluyen supervisión periódica del director, reducción de la carga horaria o tutorías/mentoring con profesores con experiencia. Concretamente, el $68 \%$ de los directores asegura no contar con ninguno de dichos programas, aunque el $46 \%$ confirma la existencia de actividades informales - trabajo informal y jornadas de acogida para nuevos docentes. En general, en la mayoría de países europeos se observa lo contrario: muchos programas formales estructurados, los cuales han evidenciado un impacto positivo sobre el nivel de desempeño de los profesores y el rendimiento de los estudiantes (Ingersoll y Strong, 2011) y pocas actividades de carácter informal. En este sentido, llama la atención que todos los países de la región norte y algunos otros de la región central, además de contar con programas de supervisión por parte del director o profesores con más experiencia, recurren a la reducción de horas de trabajo para que profesores noveles puedan prepararse y afianzarse en la tarea de enseñar.

Por último, todos los directores europeos coindicen en que los programas de mentoring sirven de apoyo a los profesores con menos experiencia, mejoran las competencias pedagógicas de los profesores, favorecen la colaboración entre profesores, inciden positivamente en los resultados del alumnado y contribuyen a fortalecer la identidad profesional.

Por su parte, la Figura 4 incluye los resultados vinculados al profesorado. 


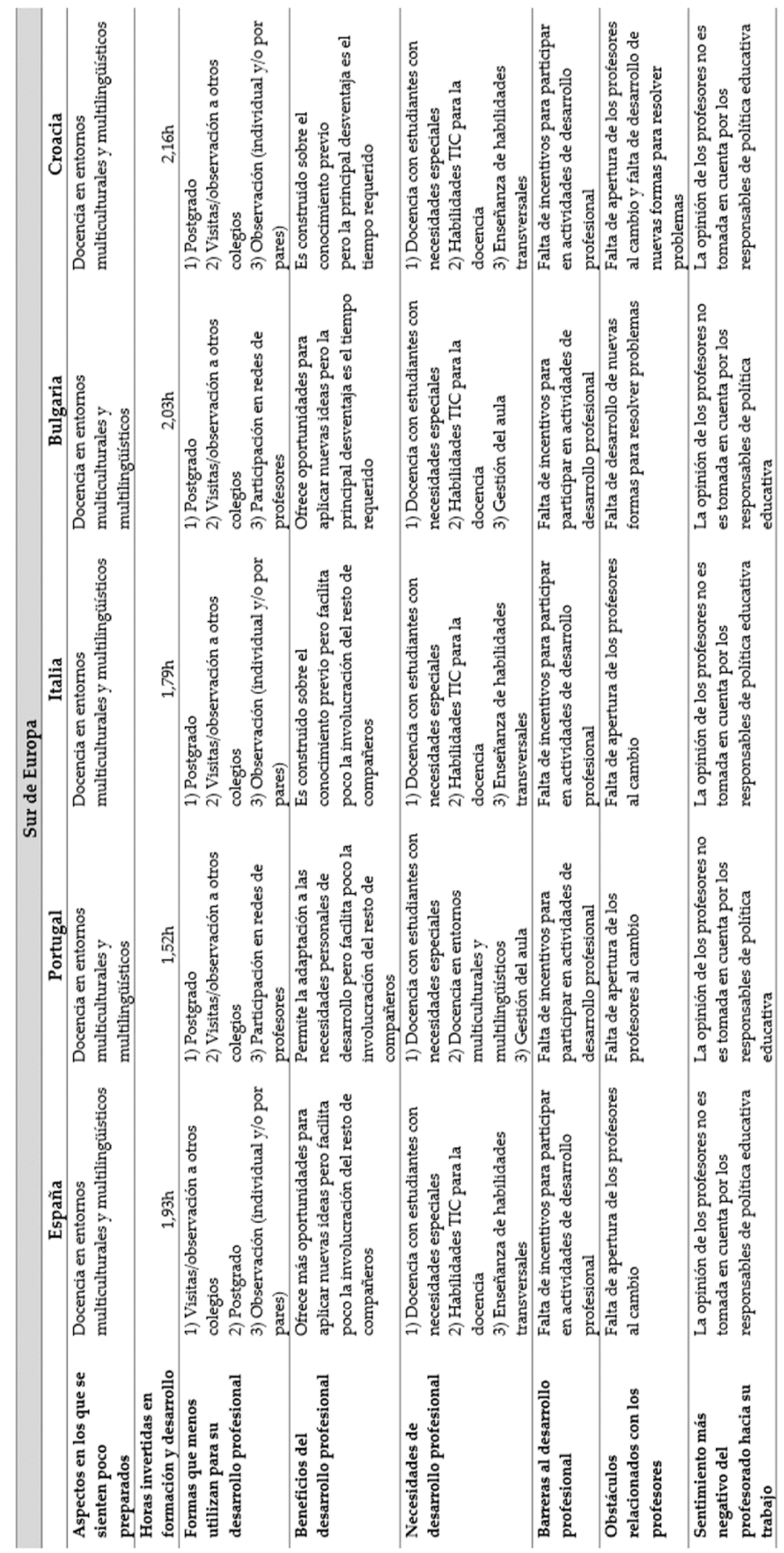




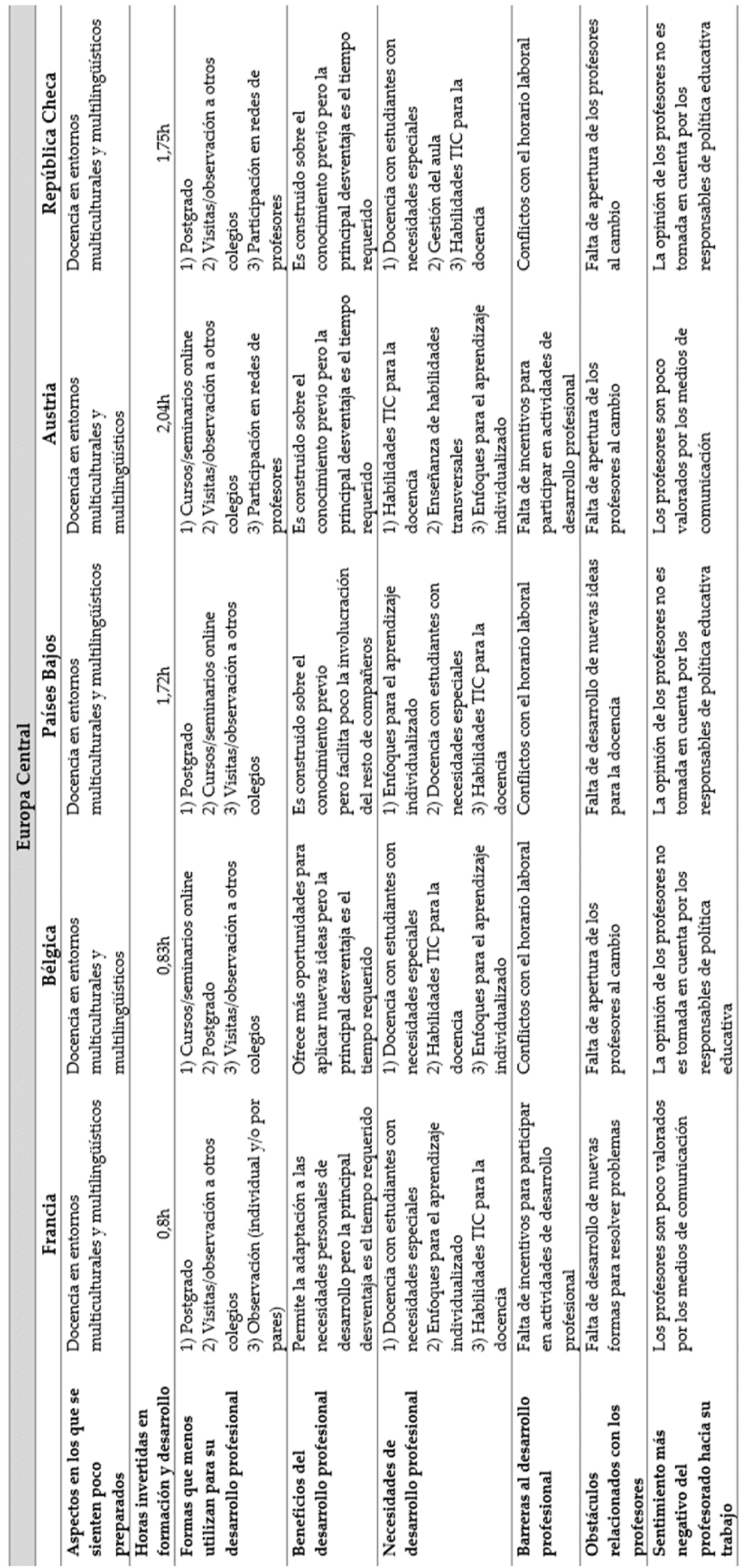




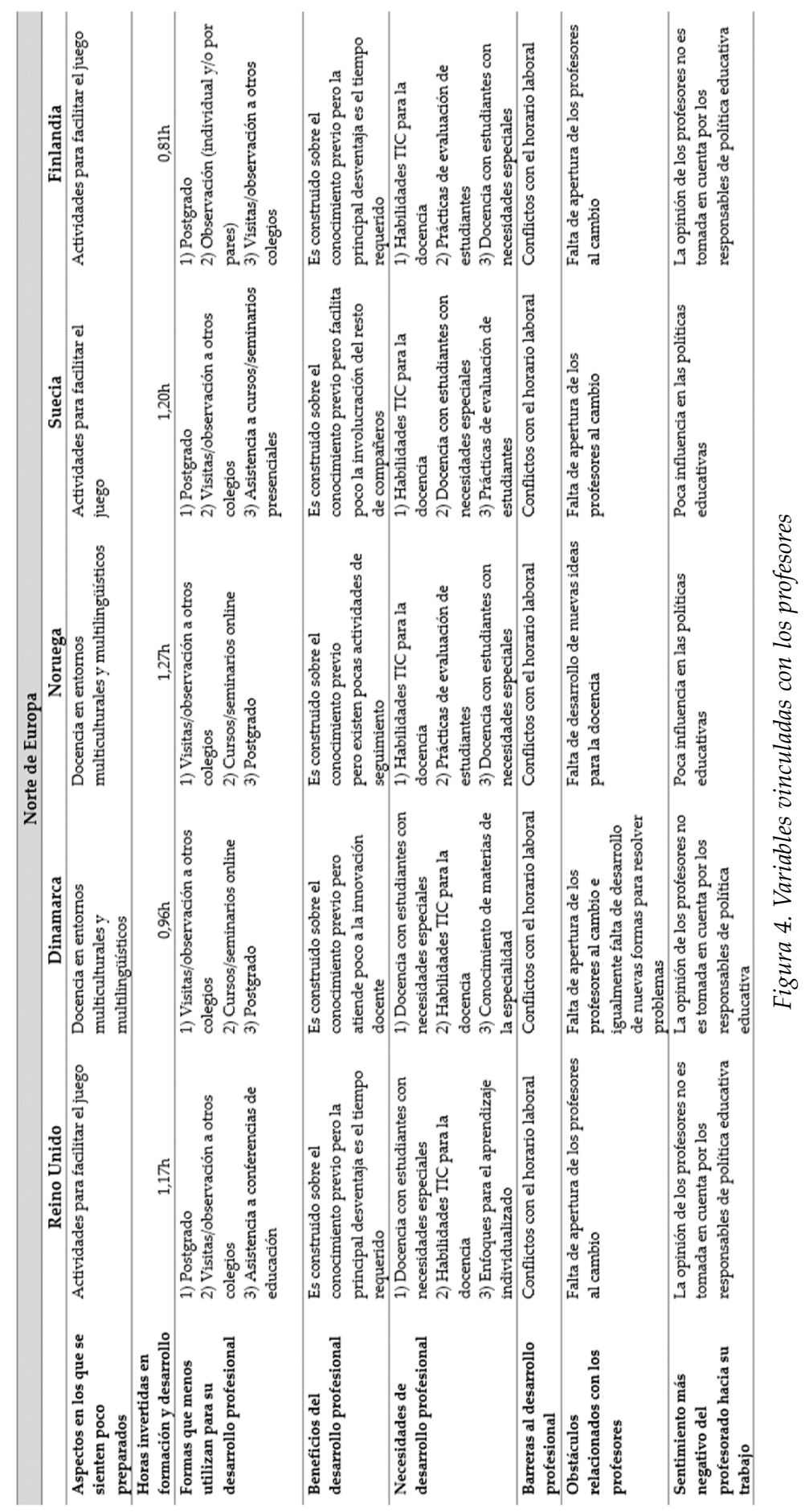


La docencia en entornos multiculturales y multilingüísticos aparece para los profesores de la mayoría de los sistemas educativos como el aspecto en el que se sienten menos preparados -ello puede deberse al desafío que supone el cambio demográfico por la cantidad de población migrante. Sin embargo, en algunos países nórdicos, habiendo expresado los profesores sentirse en general bien preparados en el conocimiento de sus materias, en competencias pedagógicas o el conocimiento del currículo, el aspecto que en el que sienten una menor preparación se refiere a las formas de facilitar el juego en el proceso de enseñanza y aprendizaje.

Los profesores españoles reconocen invertir, de media, 1,93 horas a la semana en actividades de formación y desarrollo profesional - en su mayoría las dedican a asistir a seminarios y cursos presenciales u online. Esta cifra, junto con la del resto de países mediterráneos y Austria, llama la atención por ser una de las más altas de toda Europa. Sin embargo, para los países del norte europeo y algunos de la región central, esta media se sitúa en torno a 1 hora. En estos sistemas pudiera ser requerida una menor cantidad de horas de formación y desarrollo a la semana, por un lado, por la más exigente preparación previa del profesorado y, por otro, por una mayor efectividad de los métodos. Como puede comprobarse, al contrario de lo que sucede en España y otros países del sur europeo, estos países aplican con frecuencia técnicas de tutoría y/u observación entre compañeros y redes de profesores que parecen tener un impacto más efectivo que la asistencia a cursos y seminarios - dichas técnicas impactan en múltiples facetas de la labor del docente a través de la orientación, guía, apoyo y colaboración e influyen en los comportamientos futuros del profesorado (OECD, 2019b). De hecho, son los sistemas que apenas recurren a estas formas y técnicas de desarrollo profesional los que apuntan como mayor desventaja que, en general, los métodos utilizados fomentan el individualismo y tienen escasa capacidad para involucrar al resto de compañeros.

En general, las áreas en las que los profesores españoles demandan más formación y desarrollo coinciden con las de todos los países europeos. La enseñanza al alumnado con necesidades educativas especiales o capacidades dispares y las habilidades TIC para la docencia son, con alguna pequeña excepción, las dos principales peticiones de todos los profesores europeos. Además, son muchos también los que reclaman una mayor formación en la enseñanza de destrezas transversales - por ejemplo, creatividad, pensamiento crítico o resolución de problemas - y en los enfoques para el aprendizaje individualizado. Docentes españoles subrayan, en relación a las prioridades de gasto, que es necesaria una mayor inversión destinada a ofrecerles un desarrollo profesional de alta calidad.

En línea con las respuestas de los directores, los profesores españoles y los de todos los sistemas educativos de la región sur y algunos de Europa central acusan la falta de incentivos como el factor que más obstaculiza su desarrollo profesional -específicamente, el $76 \%$ de los docentes españoles lo señala como el motivo más preocupante, frente al $48 \%$ del profesorado de la OCDE (OECD, 2019b). Por el contrario, otros países centrales y todos los del norte de Europa apuntan la incompatibilidad con el horario laboral como el mayor impedimento.

En un ejercicio de introspección y crítica colectiva, el profesorado español, al igual que el de la mayoría del resto de países europeos, manifiesta que la falta de apertura del personal docente al cambio es el principal freno para el avance y el éxito de sus centros educativos y, por tanto, para la mejora de la calidad de la educación. En este 
sentido, la resistencia al cambio por parte del profesorado viene motivada por factores de índole personal-emocional, factores de carácter profesional y, por último, factores de naturaleza institucional. Tales factores suelen presentarse de forma combinada, incrementándose así las resistencias y situaciones de inmovilismo (Monereo, 2010).

El profesorado europeo en su mayoría también coincide en que las autoridades competentes y los responsables de las políticas educativas toman poco o nada en cuenta su opinión a la hora de tomar decisiones y aplicar nuevas medidas - en el promedio de la OCDE sólo el 14\% de los docentes aseguran sentir valorada su opinión (OCDE, 2019b). Concretamente, en España, las continuas reformas educativas han sido duramente criticadas, entre otros motivos, por haber mantenido al profesorado alejado de su gestación, siendo éstos meros aplicadores. Esto es, las leyes y reformas han sido pensadas 'desde arriba' por un grupo de políticos y especialistas y han descendido a los docentes, quienes reclaman una mayor participación y consulta.

En definitiva, este análisis evidencia, por un lado, que la mayoría de sistemas educativos europeos se enfrenta a similares dificultades, obstáculos y demandas: en general, el sentir de directores y profesores es el mismo en numerosos aspectos relacionados con sus necesidades de formación y desarrollo y sus exigencias para incrementar la calidad de la enseñanza, los frenos y trabas que dificultan el funcionamiento de los centros y las sensaciones de que son tenidos poco en cuenta ante la formulación de nuevas políticas educativas. No obstante, por otro lado, este estudio también pone de relieve que el sistema educativo español difiere - no tanto con el resto de países de la región sur pero sí con algunos centrales y, sobre todo, con los del norte de Europaen aspectos que podrían marcar una diferencia sustancial en sus resultados. La escasa participación de los directores en programas de liderazgo que resulta en la práctica de un liderazgo escolar empobrecido, la reducida presencia en los centros de programas formales estructurados de inducción y de técnicas de tutoría y observación entre compañeros como fórmula efectiva en la capacitación docente y, por último, la falta de incentivos al desarrollo profesional se proponen como los principales ejes disonantes.

\section{Conclusiones}

Este trabajo precisa en qué aspectos el sistema educativo español se asemeja o difiere de aquéllos que sistemáticamente alcanzan mejores resultados y encabezan los rankings de éxito escolar a nivel mundial (esto es, los de los países de la región norte de Europa y algunos de Europa central como Países Bajos y Bélgica). Sorprenden, primeramente, las numerosas similitudes que directores y docentes europeos ponen de relieve en relación al prestigio y la dificultad para atraer talento a la profesión docente, a la necesaria colaboración docente y la apertura del profesorado a los cambios o a las exigencias formativas en la enseñanza de alumnado diverso y en contextos multiculturales, así como en habilidades TIC, entre otras - las medias y desviaciones típicas revelan tendencias y dispersiones muy similares. Sin embargo, España diverge y dista de la mayoría de sistemas educativos en tres aspectos clave: 1) las fórmulas de entrada a la profesión docente y la formación inicial; 2) el liderazgo, el empoderamiento y la capacidad para potenciar y explotar de manera continua el talento docente; y 3) la gestión de las carreras profesionales. 
Por ello, el primer replanteamiento debe poner el foco de atención en la fase de iniciación a la profesión docente; esto es, en las etapas de reclutamiento, selección y socialización. El objetivo prioritario del reclutamiento y selección de candidatos es atraer y elegir aspirantes que muestren altos niveles de cualificación y motivación intrínseca, implicando ello en España un cambio en los procedimientos de acceso a la profesión - tal y como se hace en países como Reino Unido, Finlandia o Suecia, entre otros, donde se añaden requisitos de acceso a la formación inicial, siendo necesario superar un proceso estructurado obligatorio para confirmar la capacidad para la docencia (Eurydice, 2018). En España, pese a los esfuerzos por mejorar la formación inicial del profesorado, éste recibe, respecto al promedio de la OCDE, menos formación en contenidos de su materia, didáctica y práctica en el aula, y es que la duración y el contenido durante la fase de preparación de nuevos docentes puede marcar la diferencia (OECD, 2019b). Como sucede en otros muchos países, el sistema educativo español tiene dificultad para atraer a la profesión docente a los mejores estudiantes ante la desvalorización y desprestigio de ésta - sólo un $26 \%$ de los profesores de la OCDE sostiene que el trabajo docente está bien valorado por la sociedad (OECD, 2019d). Es por ello que las autoridades educativas deberían repensar la estrategia de mejora del atractivo de la profesión en su conjunto.

Cambios en la política de acceso también resultan aplicables a los directores españoles, cuyo modelo de selección es uno de los menos extendidos en Europa. La selección de líderes escolares en España se basa en la valoración de méritos y la realización de un proyecto de dirección, mientras que la tendencia europea se centra en la contratación abierta o en la creación de un cuerpo funcionarial directivo consolidado. Dada la dificultad que plantea la primera fórmula por la estructura y organización del sistema educativo español, la creación de un cuerpo funcionarial directivo - similar al modelo francés, el cual otorga numerosos poderes y responsabilidades al director (Segura, 2009) - podría ser una buena alternativa para profesionalizar la dirección escolar y evitar la escasez de candidaturas a la dirección.

Por lo que respecta a la socialización laboral inicial tanto de profesores como de directores, los métodos formales de inducción como las tutorías/mentoring han demostrado ser útiles para fomentar el aprendizaje y contribuir a la definición de las creencias, valores y competencias docentes (OECD, 2019b). Dar más cabida a programas de tutorización por parte de profesores o directores experimentados podría, sin duda, proporcionar a los noveles una formación inicial y capacitación previa de mayor calidad, asegurando desde el comienzo de su carrera docente una base de conocimientos y competencias sólida y fortaleciendo la profesionalidad (OECD, 2019d). De manera específica, en el caso de los directores, también se hace necesario promover, desde el principio, una mayor participación en actividades que faciliten la adquisición y estimulación de habilidades de liderazgo escolar y que permitan impactar más acusadamente en la gestión eficaz del profesorado y de los centros educativos.

El segundo replanteamiento habría que centrarlo en la formación continua y el desarrollo profesional, debiendo garantizarse la alineación sistemática y complementariedad entre ésta y la formación inicial mediante la colaboración entre los diferentes actores implicados en tales procesos formativos. Para ello, en primer lugar, es necesario identificar las necesidades y demandas del personal docente y diseñar programas 
acordes con ellas. Directores españoles, en línea con la mayoría de sus homólogos europeos, dirigen sus exigencias hacia una mayor formación en métodos colaborativos, habilidades de liderazgo y el diseño de actividades de desarrollo profesional para el profesorado. Dicha formación cobra especial sentido en los sistemas que ofrecen una mayor autonomía a los directores para adaptarse a sus contextos y responder a sus necesidades específicas. En España, el nivel de autonomía otorgado a los directores dista mucho del amplio margen del que disfrutan otros directores europeos (OECD, 2019d). Frente al 34\% de la OCDE o el 38\% de la Unión Europea, en España sólo el $10 \%$ de las decisiones se toman en los centros educativos (OECD, 2018b).

Por su parte, el profesorado reclama más herramientas para adaptar la metodología de enseñanza a un alumnado diverso y más formación en la enseñanza de destrezas transversales y competencias digitales - en relación a esto último, a pesar de la mayor difusión de las TIC en la educación, la preparación de algunos profesores en esta área es limitada, habiéndose tal limitación convertido en un desafío para la enseñanza online a la que ha obligado la crisis del COVID-19. Además de poder recurrir, para tal formación continua, a métodos comúnmente utilizados como los cursos y seminarios presenciales u online, se debería poner un mayor énfasis en el fomento de los programas de observación y retroalimentación entre pares, no sólo por la magnitud del impacto positivo sobre las prácticas de enseñanza y el rendimiento de los estudiantes, sino también por la reducción que puede suponer en los costes de la capacitación (Kraft, Blazar y Hogan, 2018). Empoderar a los docentes a través de mayores oportunidades para el desarrollo y progreso profesional, con el consiguiente efecto sobre su nivel de competencias, podría también contribuir a enriquecer el debate político y mejorar su participación en las decisiones sobre política educativa.

Por último, el tercer replanteamiento se encuentra ligado a los incentivos que ofrece el sistema español para promover el desarrollo profesional y la gestión de las carreras profesionales. Respecto al promedio de la OCDE-28, España posee bajas tasas de participación y bajo nivel de apoyo a las actividades de desarrollo profesional, causadas principalmente por la falta de incentivos, la inadecuación de la oferta formativa y la falta de apoyos monetarios y/o no monetarios (INEE, 2019). En este sentido, una forma de levantar las barreras a la participación en el desarrollo profesional pasaría por diseñar sistemas de promoción (tanto en términos de jerarquía como de diversificación de tareas) que reconozcan y recompensen la implicación y el compromiso con la mejora del desempeño docente. De esta forma, el sistema español, que actualmente cuenta con carreras profesionales planas para los perfiles docentes de primaria y secundaria, se asemejaría a los sistemas europeos más avanzados — por ejemplo, Reino Unido o Suecia, entre muchos otros - , los cuales organizan sus estructuras de carrera de manera jerárquica en niveles formales ascendentes que implican una mayor complejidad de tareas y responsabilidades y conllevan un incremento salarial (Eurydice, 2018).

Si bien es cierto que muchas de estas cuestiones (y conjeturas) llevan años en el centro del debate educativo español, este trabajo supone una evidencia que puede ayudar a enfocar una reforma integral y consensuada a fin de elevar la educación española a altos niveles competitivos en el marco europeo. Directores y profesores, como input más valioso, se posicionan, por tanto, en el epicentro de dicha reforma en aras de combatir las rémoras que restan profesionalidad y calidad al sistema español. 
Aun conscientes de las diferencias regionales que existen en España, incrementar el valor del sistema educativo en su conjunto traería consigo un efecto positivo sobre la competitividad nacional. De hecho, son los países europeos más avanzados en términos de gasto público en educación y en resultados educativos - Finlandia, Suecia, Noruega, Reino Unido, Dinamarca, Países Bajos y Bélgica - los que presentan los modelos económicos con mayores índices de innovación y productividad (ver, por ejemplo, el Índice de Competitividad Global o el European Regional Competitiveness Index). Además del impacto sobre la competitividad, el progreso de la educación también resulta clave para el bienestar social, y más ante las temidas consecuencias económicas y sociales que, a corto y medio plazo, deja la pandemia por coronavirus en España.

Finalmente, estos resultados deben interpretarse a la luz de algunas limitaciones. Una de ellas se refiere a la imposibilidad de realizar inferencias poblacionales a partir de datos de carácter muestral. Otra tiene que ver con el empleo de datos transversales, los cuales no permiten establecer relaciones causales. Por ello, podría resultar interesante aplicar este análisis de manera longitudinal utilizando los datos de todas las ediciones de TALIS.

\section{Referencias}

Bolívar, A. (2019). Una dirección escolar con capacidad de liderazgo pedagógico. Madrid: La Muralla.

Bolívar, A., Caballero, K. y García-Garnica, M. (2017). Evaluación multidimensional del liderazgo pedagógico: claves para la mejora escolar. Ensaio: Avaliação e Políticas Públicas em Educação, 25(95), 483-506. http://dx.doi.org/10.1590/s0104-40362017002500780

Campos-García, I. (2017). Igualdad de género en las enseñanzas no universitarias en España: Un estudio descriptivo (1999-2013). Revista Complutense de Educación, 28, 1009-1025. https://doi.org/10.5209/RCED.51000

Desimone, L.M. (2009). Improving Impact Studies of Teachers' Professional Development: Toward Better Conceptualizations and Measures. Educational Researcher, 38(3), 181-199. https://doi.org/10.3102/0013189X08331140

European Commission (2019). Education and Training Monitor 2019. Recuperado de https://ec.europa.eu/education/sites/education/files/document-library-docs/et-monitor-report-2019-spain_en.pdf

Eurostat (2020a). Government expenditure on education. Recuperado de https:// ec.europa.eu/eurostat/statistics-explained/index.php/Government_expenditure_ on_education\#Expenditure_on_.27education.27

Eurostat (2020b). Euro indicators. Recuperado de https://ec.europa.eu/eurostat/ documents/2995521/10159296/3-30012020-AP-EN.pdf/b9a98100-6917-c3ea-a544ce288ac09675

Eurydice (2018). Teaching careers in Europe: Access, progression and support. Recuperado de https://eacea.ec.europa.eu/national-policies/eurydice/content/teaching-careerseurope-access-progression-and-support_en

Fuertes Camacho, M.T. (2011). La observación de las prácticas educativas como elemento de evaluación y de mejora de la calidad en la formación inicial y continua 
del profesorado. Revista de Docencia Universitaria, 9(3), 237-258. https:/dx.doi. org/10.4995/redu.2011.11228

Gálvez, I.E. (2010). El acceso a la profesión docente en España en perspectiva europea. Algunas reflexiones orientadas a la mejora de la selección del profesorado. Educación XX1, 13(2), 47-67.

García Perales, N. y Martín Sánchez, M.Á. (2012). Algunas notas en perspectiva comparada sobre formación de maestros: el caso de España y Finlandia. Tejuelo, 13, 70-87.

INE (2020). Tasas de paro por sexo y grupos de edad. Recuperado de https:/www.ine.es/ jaxiT3/Tabla.htm? $\mathrm{t}=4086 \& \mathrm{~L}=0$

INEE (2019). Sistema estatal de indicadores de la educación. Recuperado de https://www.educacionyfp.gob.es/inee/dam/jcr:efa745d7-27ec-4814-9e90-11e01957c39d/seie-2019.pdf

INEE (2020). Panorama de la educación: Indicadores de la OCDE 2020. Informe español. Recuperado de https://sede.educacion.gob.es/publiventa/panorama-de-la-educacion-indicadores-de-la-ocde-2020-informe-espanol/espana-estrategias-y-politicaseducativas-organizacion-y-gestion-educativa/24151

Ingersoll, R.M. y Strong, M. (2011). The impact of induction and mentoring programs for beginning teachers: A critical review of the research. Review of Educational Research, 81(2), 201-233. https://doi.org/10.3102/0034654311403323

Kools, M. y Stoll, L. (2016). What Makes a School a Learning Organisation?. OECD Education Working Papers, No. 137. Paris: OECD Publishing.

Kraft, M.A., Blazar, D. y Hogan, D. (2018). The effect of teacher coaching on instruction and achievement: A meta-analysis of the causal evidence. Review of Educational Research, 88(4), 547-588. https://doi.org/10.3102/0034654318759268

Manso, J., Matarranz, M. y Valle, J.M. (2019). Estudio supranacional y comparado de la formación inicial del profesorado en la Unión Europea. Profesorado: Revista de currículum y formación del profesorado, 23(3), 15-33.

Monereo, C. (2010). ¡Saquen el libro de texto! Resistencia, obstáculos y alternativas en la formación de los docentes para el cambio educativo. Revista de Educación, 352, 583-597.

Muñoz, J.M.E. (2010). La selección y la evaluación del profesorado. Revista Interuniversitaria de Formación del Profesorado, 24(2), 201-221.

Nieto, J.M. y Alfageme-González, M.B. (2017). Enfoques, metodologías y actividades de formación docente. Profesorado. Revista de Currículum y Formación de Profesorado, 21(3), 63-81.

OCDE (2018a). Effective teacher policies: Insights from PISA. Paris: PISA. OECD Publishing.

OECD (2008). Improving School Leadership - Volume 1: Policy and Practice. Paris: OECD Publishing.

OECD (2018b). Panorama de la Educación: Indicadores de la OCDE 2018. Informe español. Recuperado de https://www.educacionyfp.gob.es/inee/dam/jcr:2cba4aaa-4892-40d7ac8b-00efbc95b8a2/Panorama\%20de\%20la\%20Educacion\%202018_final.pdf

OECD (2019a). Panorama de la Educación: Indicadores de la OCDE 2019. Informe español. Recuperado de https://www.educacionyfp.gob.es/dam/jcr:b8f3deec-3fda-4622-befb386a4681b299/panorama\%20de\%20la\%20educaci\%C3\%B3n\%202019.pdf 
OECD (2019b). TALIS 2018 Results (Volume I): Teachers and School Leaders as Lifelong Learners. Recuperado de https://www.educacionyfp.gob.es/inee/dam/jcr:2dc7e7e79492-4735-a50d-3b1ae67c4242/talis-2018-informe-internacional-volumen-1-eng.pdf

OECD (2019c). PISA 2018 in Spain. Recuperado de https://gpseducation.oecd.org/Cou ntryProfile? primaryCountry $=$ ESP\&treshold $=10 \&$ topic $=$ PI

OECD (2019d). TALIS 2018 Results (Volume II) : Teachers and School Leaders as Valued Professionals. Recuperado de https://www.oecd-ilibrary.org/sites/19cf08df-en/1/2/2/ index.html?itemId=/content/publication/19cf08df-en\&_csp_ $=67 \mathrm{e} 65 \mathrm{~b} 72 \mathrm{be} 0 \mathrm{~b} 468 \mathrm{ed} 3 \mathrm{~d}$ ac915593716de\&itemIGO=oecd\&itemContentType=book\#s21

Rubio, J.G. (2017). Los resultados académicos antagónicos de la escuela comprensiva en España y en Finlandia. MULTIárea. Revista de didáctica, (9), 194-213.

Segura, M.R.O. (2009). ¿Es posible la autonomía escolar? El papel de la dirección y de los proyectos del centro en los sistemas educativos francés, italiano y español. Educación XX1, 12(1), 151-180. https://doi.org/10.5944/educxx1.1.12.291

Tiana, A. (2011). Políticas de formación del profesorado y mejora de los sistemas educativos: algunas reflexiones a partir de la experiencia española. Revista Fuentes, $11,13-27$.

Ulloa, J. y Gajardo, J. (2016). Observación y retroalimentación docente como estrategias de desarrollo profesional docente. ÍNDICE, 83-95.

Granados, L.P. (2015). Análisis de las pruebas de acceso a la formación de docentes en España y Finlandia: conocimientos o competencias. Revista Complutense de Educación, 26(3), 591-609. https://doi.org/10.5209/rev_RCED.2015.v26.n3.44448

Fecha de recepción: 20 de enero de 2021.

Fecha de revisión: 11 de febrero de 2021.

Fecha de aceptación: 31 de mayo de 2021. 

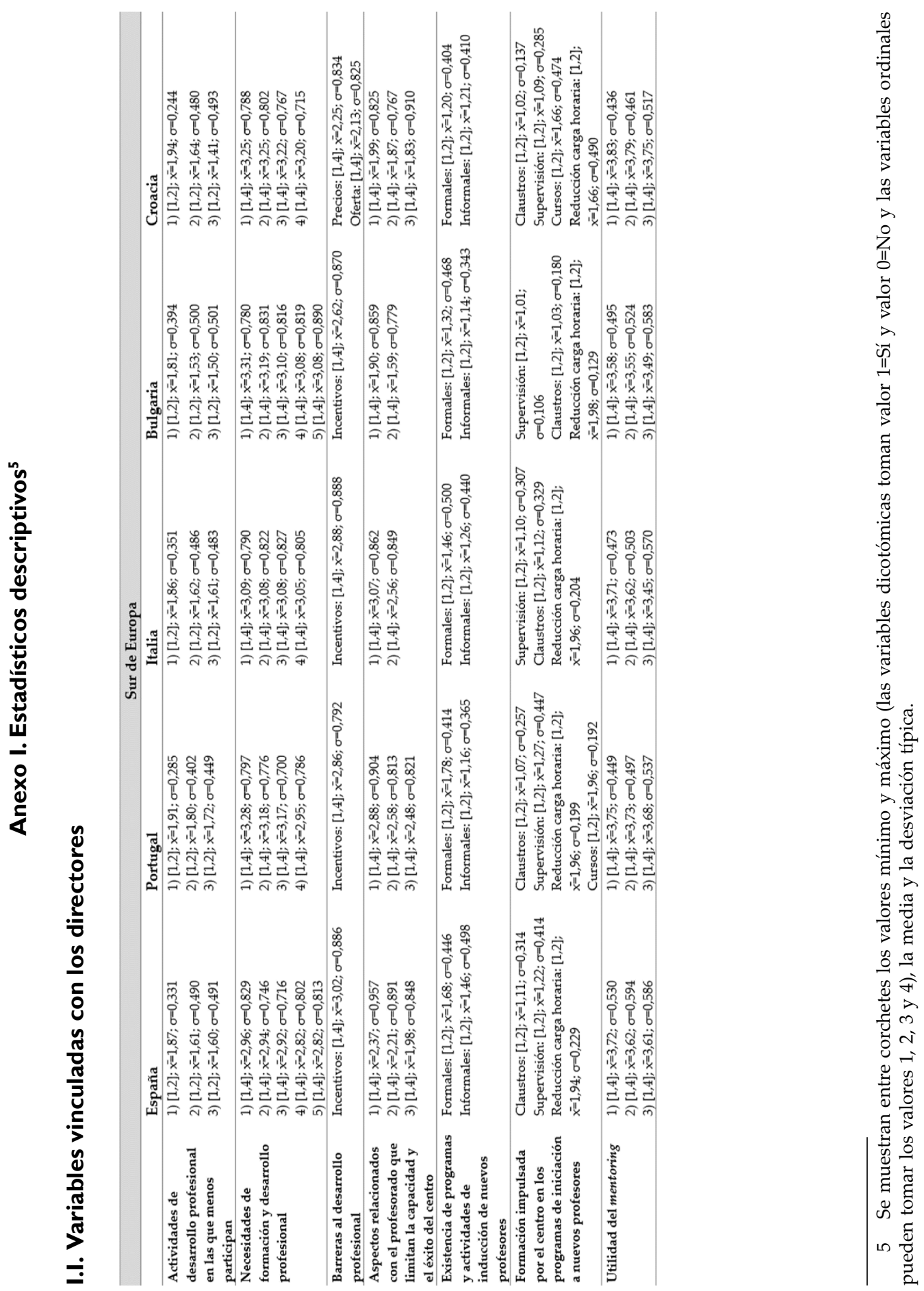


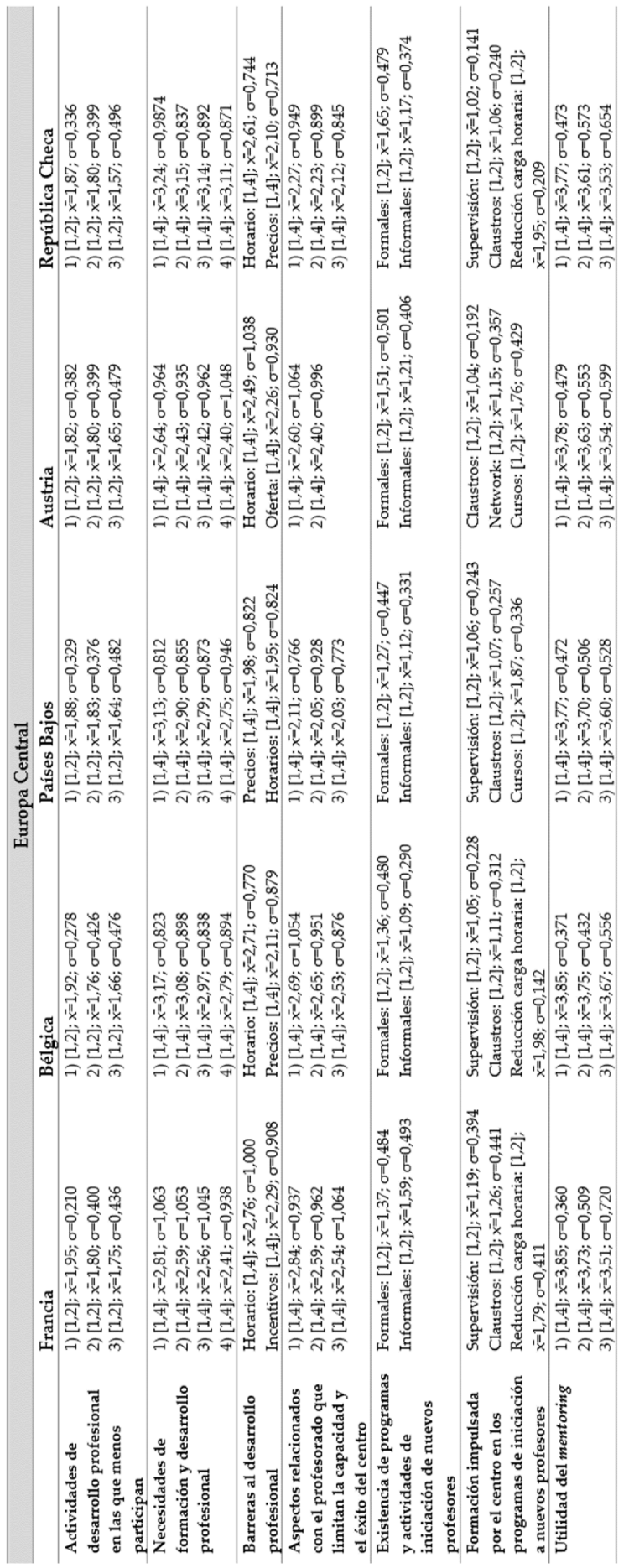




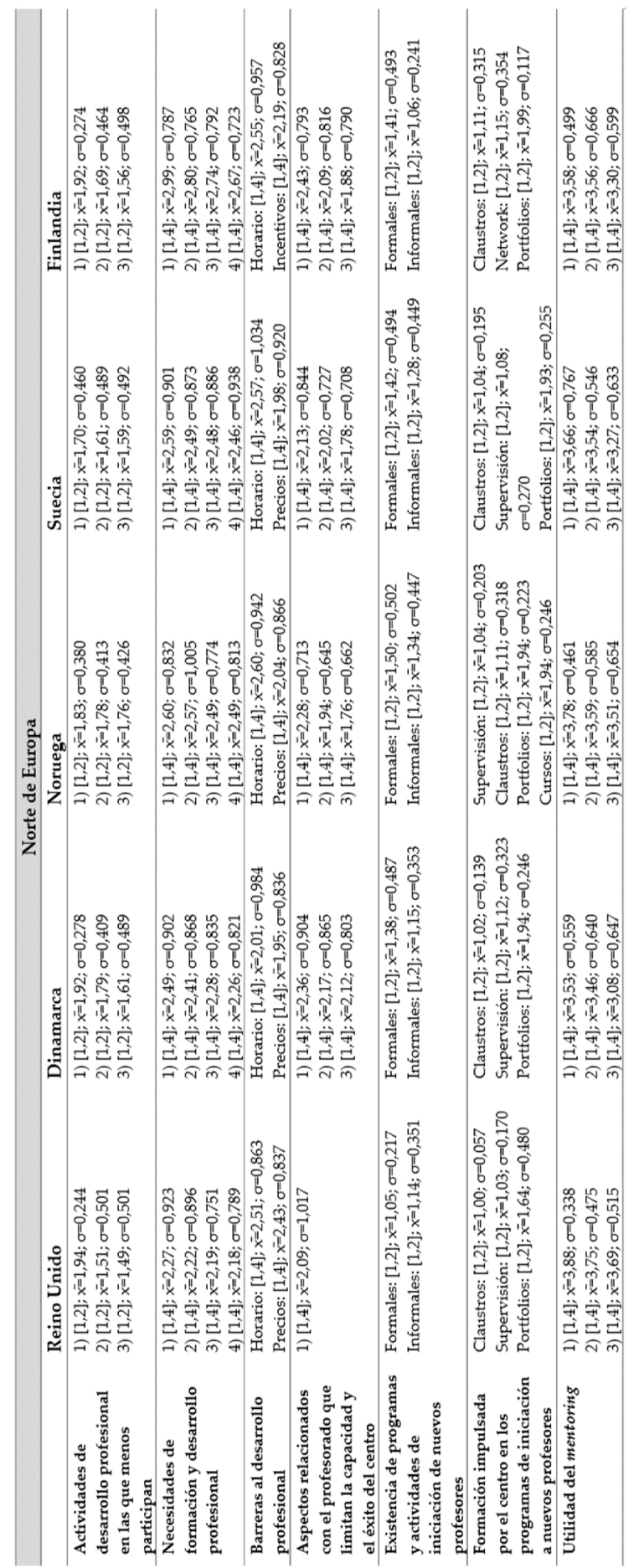




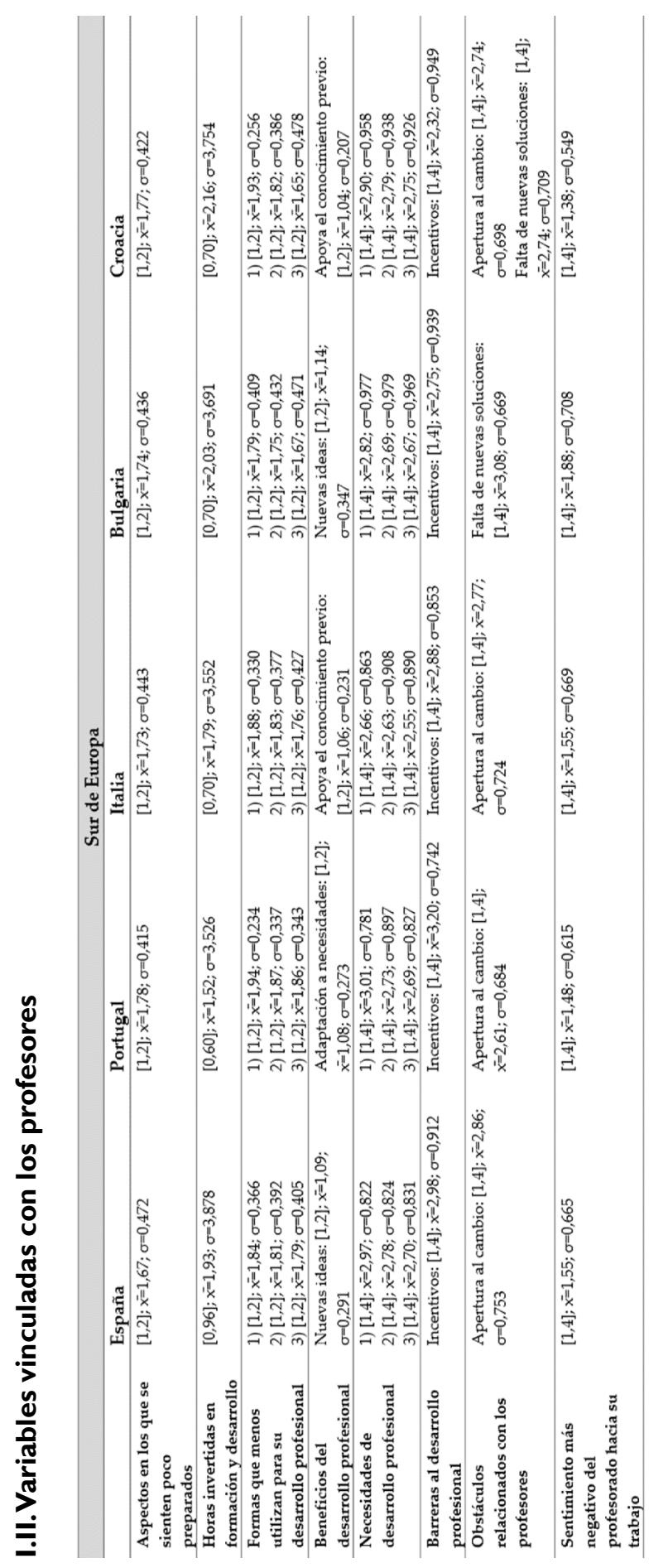




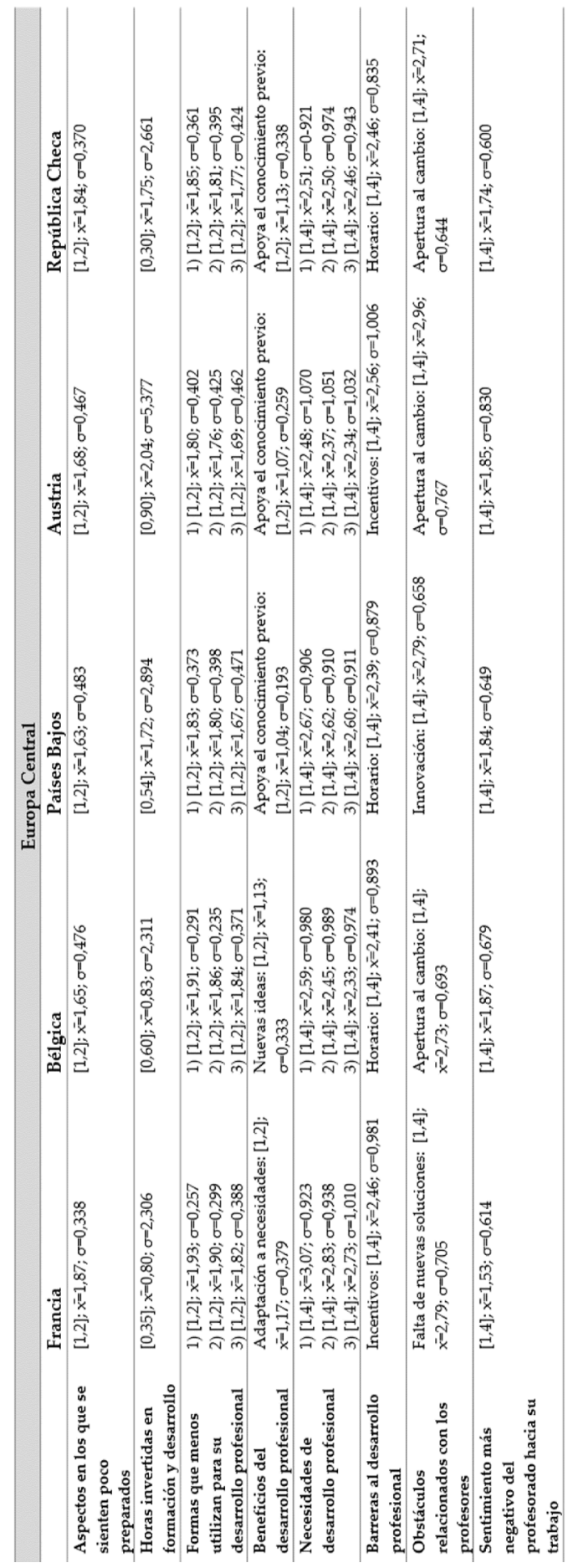




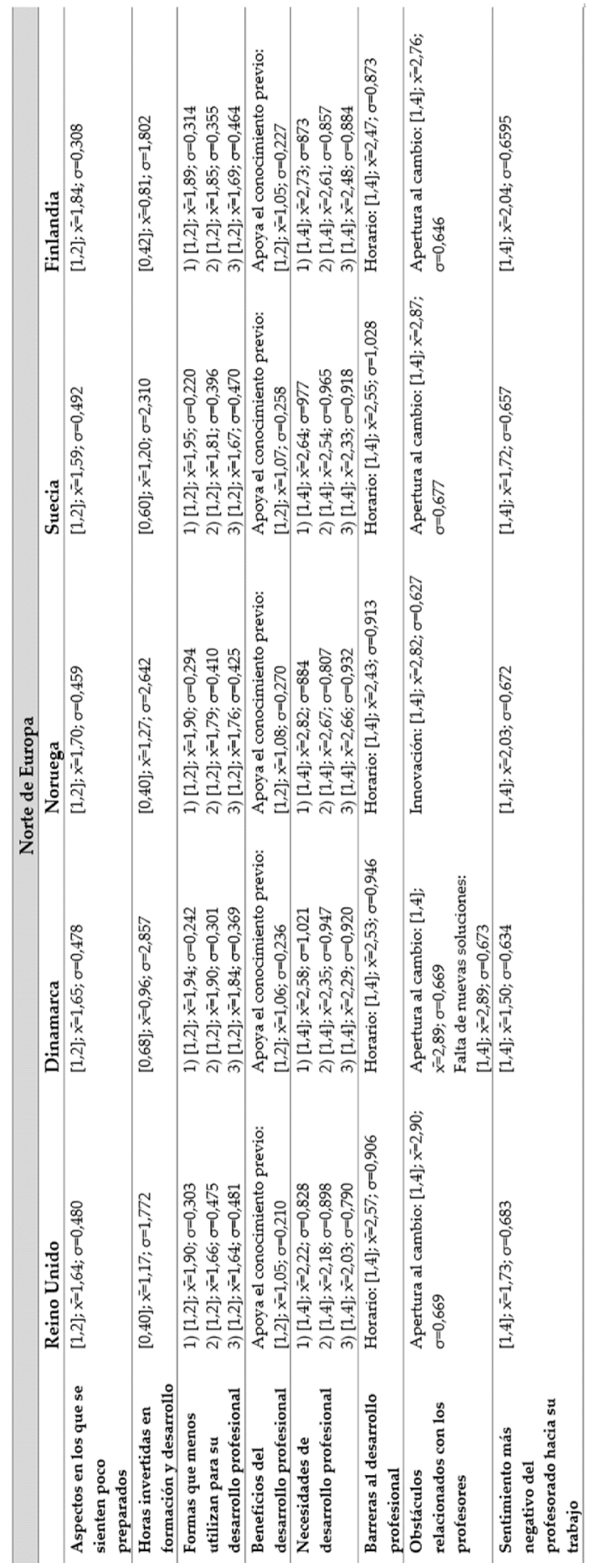

